\title{
Aplicación de Nuevas Tecnologías en la Docencia Universitaria
}

\author{
Rocio Maceiras ${ }^{1}$, Ángeles Cancela ${ }^{1}$ y Vicente Goyanes ${ }^{2}$ \\ Universidade de Vigo, (1) Departamento de Enxeñaría Química. (2) Departamento Ingeniería \\ Telemática, E.T.S.E.I., Campus Lagoas-Marcosende, 36310 Vigo, España. \\ (e-mail: rmaceiras@uvigo.es)
}

Recibido Nov. 9, 2009; Aceptado Feb. 5, 2010; Versión Final recibida 10 Feb. 2010

\begin{abstract}
Resumen
Se presenta una aplicación de las llamadas píldoras del conocimiento en el marco de las nuevas tecnologías en la docencia universitaria, desarrolladas en la Universidad de Vigo, España. Se analiza el concepto de píldora del conocimiento y se presenta una sobre el tema de equilibrio químico de interés en Ingeniería Química y estudios afines. Las píldoras creadas tienen igual formato, y se basan en la definición de Polimedia, técnica muy valorada en desarrollos de nuevas tecnologías para la enseñanza ya que permite que el ponente interactúe con la presentación. El objetivo último de las píldoras y en particular de la discutida en este trabajo es mejorar el proceso de aprendizaje del alumno y facilitar la integración de las materias, todo esto en el marco del Espacio Europeo de Educación Superior. Se analiza finalmente la cantidad de accesos de dichas píldoras en el tiempo y se concluye sobre las ventajas de su uso como tecnología docente de apoyo a la enseñanza-aprendizaje.
\end{abstract}

Palabras Clave: docencia universitaria, objeto de aprendizaje, píldora de conocimiento, ingeniería.

\section{Application of New Technologies in University Teaching}

\begin{abstract}
An application of the so-called teaching pills as part of the program on new technologies for university formation developed at the University of Vigo in Spain is presented. The concept of teaching pill is analyzed and specifically one on the subject of chemical equilibrium of interest in Chemical Engineering and related areas is discussed. The teaching pills have all the same format that is based on the Polimedia definition, technique that is highly considered in new technology developments since it allows interaction between the speaker and the presentation. The final objective of the pills and in particular the one discussed in this paper is helping the learning process of students and facilitating the integration of subjects, all this within the requirements of the European Higher Education Space. Finally, some statistics on the access to these pills by user around the world are presented.
\end{abstract}

Keywords: university teaching, learning object, knowledge pill, engineering 


\section{INTRODUCCIÓN}

El Espacio Europeo de Educación Superior (EEES) en las universidades ha sido rediseñado en los últimos años, con el objetivo de lograr una mejora en la calidad de los estudiantes, creando un entorno más interactivo y motivador tanto para alumnos como para profesores. El proceso se inició en la definición del proceso de Bolonia en 1999 (EME, 1999). El objetivo del llamado Proceso de Bolonia es la creación de un EEES, mediante la armonización de las normas de grado académico y las normas de garantía de calidad en los países europeos en 2010. A partir de ese momento, los países pertenecientes a la Unión Europea tendrán que adaptar sus estrategias de aprendizaje y enseñanza a ciertos parámetros. Con este nuevo proceso, los estudiantes tendrán que dedicar más número de horas al trabajo personal y los profesores impartirán menos clases teóricas, sin embargo tendrán que diseñar nuevos métodos de aprendizaje con el fin de mejorar la enseñanza (Drennan y Beck, 2001; Felder y Brent, 1999).

Una de las herramientas que permiten mejorar el proceso de aprendizaje son los Objetos de Aprendizaje, que son recursos digitales y basadas en la Web, cuya característica principal es que pueden ser utilizados y reutilizados para apoyar el aprendizaje. Wiley (2002) describe los Objetos de Aprendizaje como "cualquier recurso digital que puede ser reutilizado para facilitar el aprendizaje". Dentro de estos recursos digitales se pueden incluir imágenes, videos o audios pregrabados, pequeñas porciones de texto, animaciones, pequeñas aplicaciones Web, o incluso páginas Web completas que combinen texto, imágenes y otros medios de comunicación.

En este trabajo se ha utilizado un Objeto de Aprendizaje, concretamente las Píldoras de Conocimiento, para mejorar el proceso de aprendizaje en la Escuela Técnica Superior de Ingenieros Industriales de la Universidad de Vigo. Las Píldoras de Conocimiento son pequeñas unidades de formación accesibles en Internet para los alumnos, que sintetizan contenidos fundamentales de la asignatura. Ésta píldoras permiten comprender en 15 minutos un concepto, un fenómeno, o una práctica. La ventaja de ese método de aprendizaje es que los alumnos pueden disponer de ella siempre que lo necesiten y en cualquier lugar. En la actualidad son varios los autores que investigan la aplicación de software educativo para mejorar el proceso de aprendizaje (García y Gracia, 2008; Kimovski et al., 2003; Selmer et al., 2007); sin embargo, no hay muchos estudios sobre la utilización de píldoras de conocimiento en el área de Ingeniería Química (Valderrama et al., 2009).

\section{METODOLOGÍA}

Para llevar a cabo este estudio se realizó una Píldora de Conocimiento centrada en el Equilibrio Químico, tema fundamental para el alumnado de la asignatura. Dicha píldora fue grabada en unas instalaciones pertenecientes a la Universidad de Vigo y diseñadas para dicho fin. La elaboración de las píldoras se basa en la tecnología Polimedia (Turró et al., 2009) que permite, mediante la técnica Chroma Key (Chaplin, 1993), la combinación sincronizada de una imagen generada por ordenador con la imagen y sonido del docente en un único video. El producto final es un video de alta resolución $(1280 * 768)$ que contiene al docente, su voz, la imagen existente en la pantalla del ordenador que ha utilizado durante su presentación e, incluso, los movimientos del puntero de ratón que se han producido a lo largo de la misma.

El acceso a las píldoras desarrolladas en la Universidad de Vigo es libre y la secuencia de acceso a la píldora diseñada para este trabajo se muestra en la figura 1. El esquema de la píldora es el que se muestra en la figura 1d. Como puede observarse, la pantalla se divide en dos partes, de tal forma que en una de ellas se muestra la presentación en PowerPoint, mientras que en la otra aparece la imagen del profesor. Finalmente, se produce un video de alta resolución que contiene la imagen y voz del profesor y fondo de pantalla con la presentación. La píldora de conocimiento se divide en varias partes para facilitar la comprensión por parte del alumno. En primer lugar el profesor hace una breve introducción del contenido de la totalidad de la píldora para, a continuación explicar cada uno de los conceptos necesarios para la comprensión del tema. Algunas características básicas y algunas ventajas de las píldoras docentes como apoyo a la enseñanaza-aprendizaje han sido descritas en la literatura (Valderrama et al., 2009). 


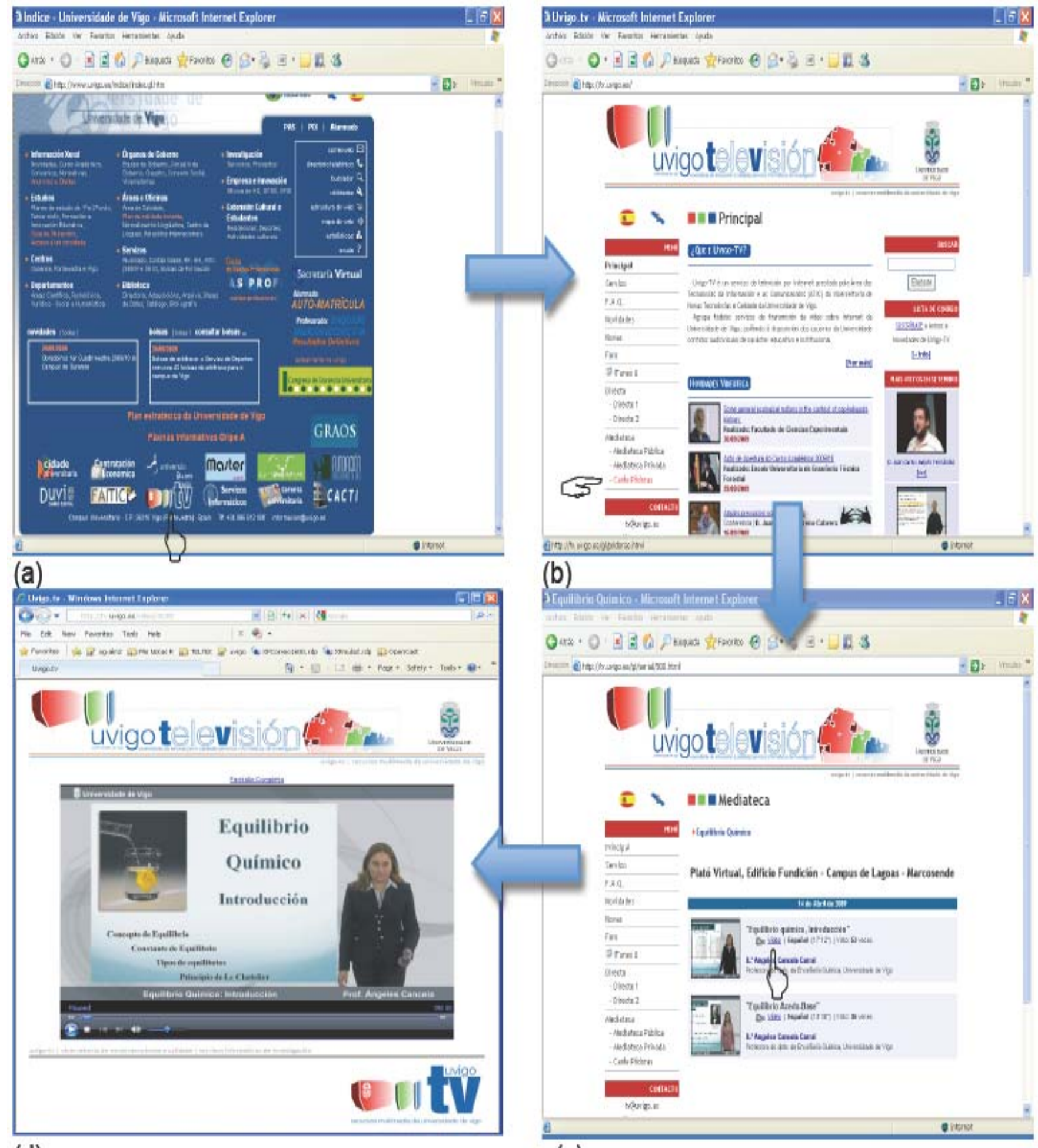

(d)

(c)

Fig. 1. Secuencia de acceso a las píldoras de conocimiento

Entre sus principales características destacan el hecho de ser objetos autónomos, estar enfocados a un tema, ser indivisibles, estar dirigidos a una audiencia específica y ser agrupables. Una de las ventajas de las píldoras de conocimiento es la sensación de comodidad por parte del profesor, ya que las píldoras son grabadas en un corto período de tiempo y además le permite utilizar herramientas para apoyar su explicación, como presentaciones en PowerPoint o cualquier otra herramienta como una pizarra electrónica. Otra ventaja es que el uso de las píldoras no genera los problemas relacionados de derechos de autor debido a la aparición de la imagen del docente en dicha píldora. 


\section{RESULTADOS Y DISCUSIÓN}

El objetivo del uso de las píldoras de conocimiento es que los alumnos entiendan los principios en lugar de memorizar los hechos. Las píldoras permiten la utilización de varios recursos como imágenes, gráficos, esquemas, que captan la atención del alumno y presentan la ventaja de que el alumno puede utilizarlas siempre que lo necesite y las veces que le sean necesarias. Debe tenerse en cuenta que las píldoras tienen una corta duración, por lo que se utilizan para que el alumno adquiera un conocimiento previo sobre el Equilibrio Químico necesarios para la resolución de problemas. Esta píldora se utiliza para dar la parte teórica del tema de Equilibrio Químico, con lo cual, el docente una vez que el alumno haya visto la píldora, empleará la clase presencial para, en primer lugar, aclarar las dudas que hayan surgido sobre los conceptos vistos en la pildora, pasando posteriormente a la resolución de ejercicios sobre el tema.

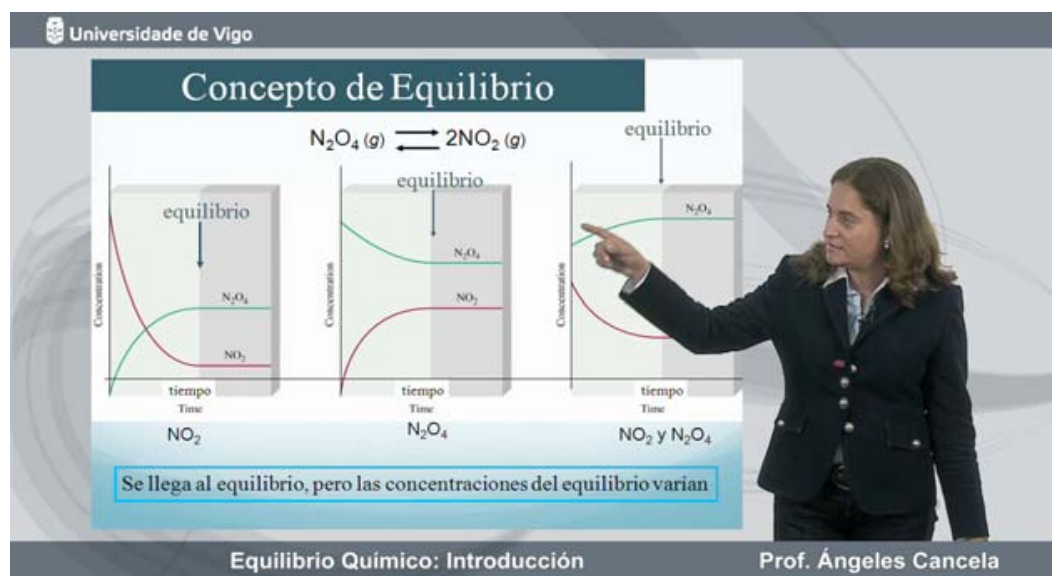

(a)

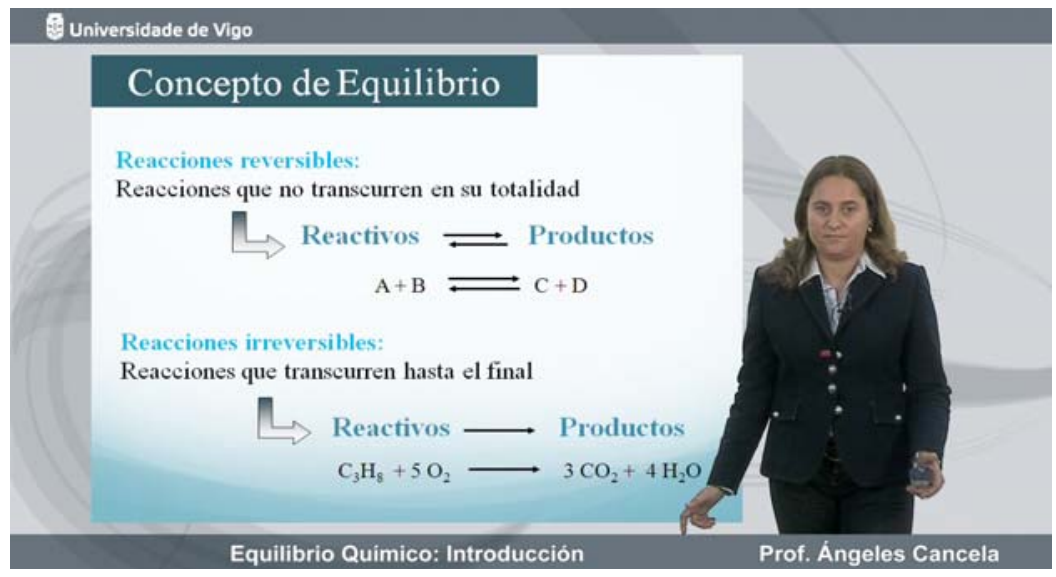

(b)

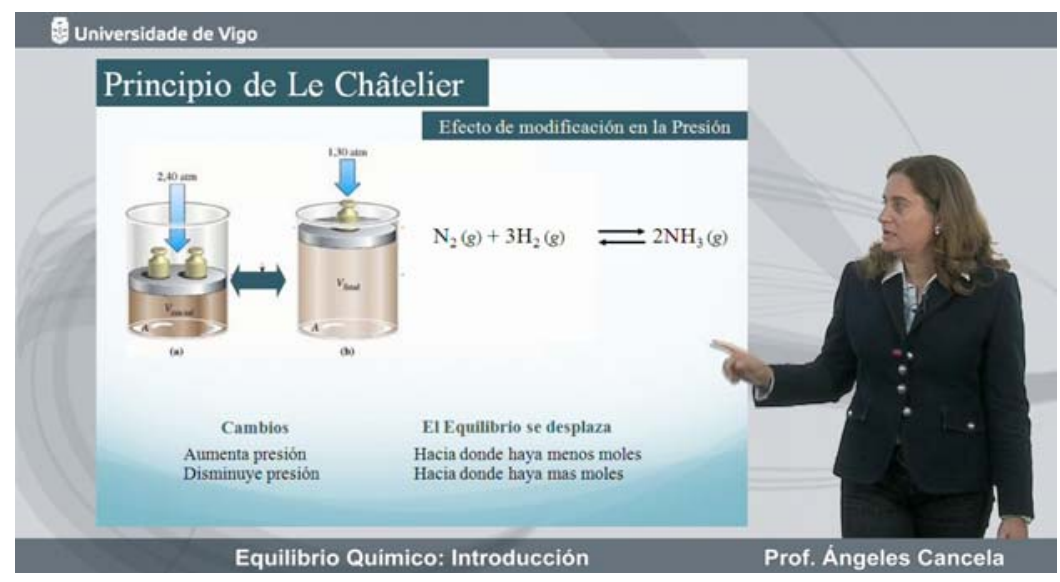

(c)

Fig. 2. Ejemplo de capturas de pantalla de la píldora. 


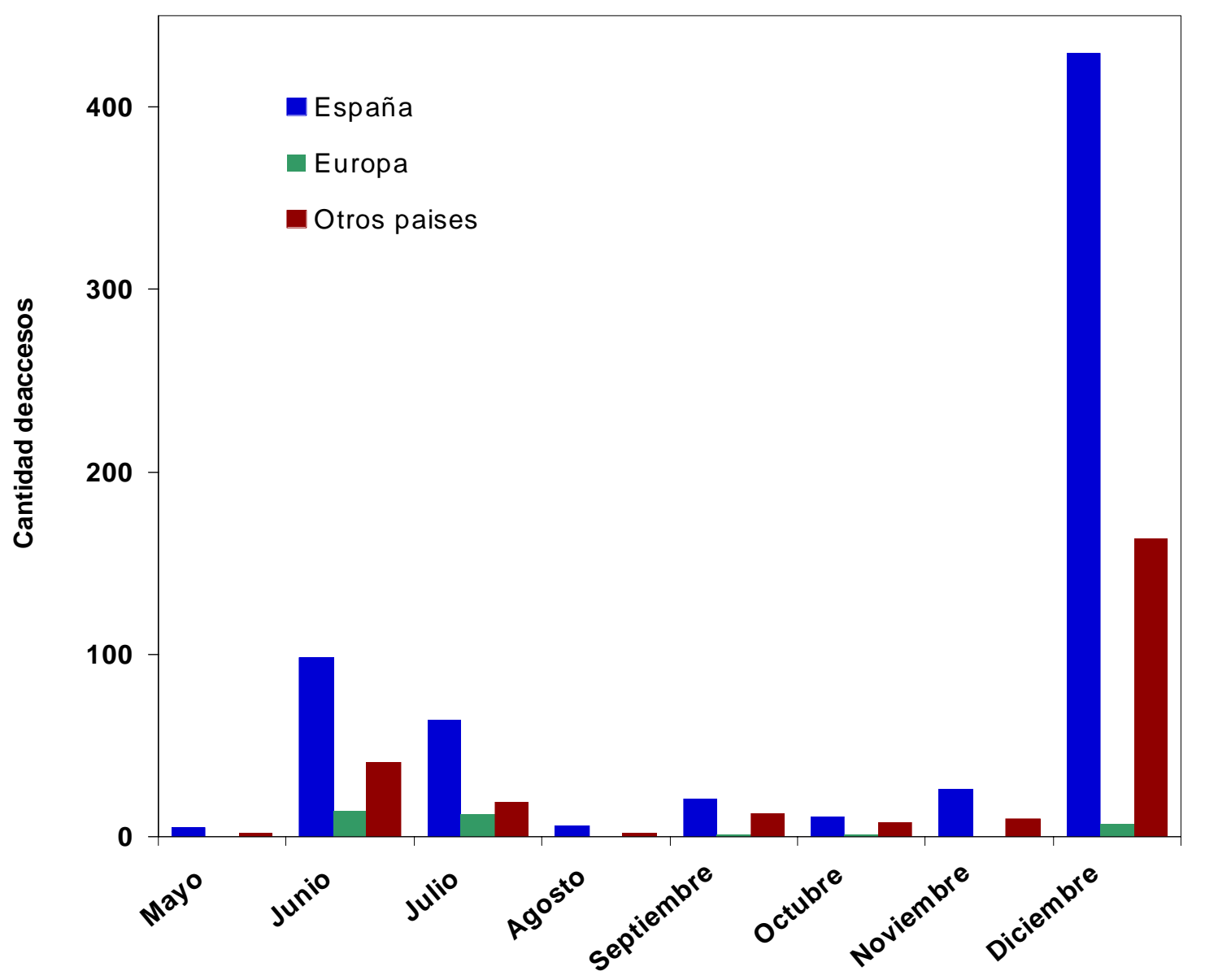

Fig. 3. Datos de uso de la píldora a nivel mundial

Como puede observarse en la Figura 2a, la docente utiliza una serie de gráficos para poder explicar el concepto del equilibrio químico con un ejemplo, pero también utiliza un esquema para que el alumno pueda distinguir entre reacciones reversibles o irreversibles (Figura 2b). Un concepto fundamental para comprender los factores que afectan al equilibrio químico es el Principio de Le Chatelier, por lo que se ha dedicado parte de la píldora a explicar este concepto. Para ello, se ha utilizado como recurso una imagen combinada con texto que permite visualizar cómo se ve modificado el equilibrio de una reacción cuando se modifica la presión del sistema (Figura 2c). Además, la tecnología permite que el profesor pueda comprobar que los alumnos han visto las píldoras, el número de veces y si la han visto en su totalidad. Como prueba de que las píldoras son utilizadas por los alumnos se muestran las estadísticas de uso para esta píldora desde mayo hasta diciembre de 2009 (Figura 3). Como se puede observar, el número de accesos aumenta considerablemente durante el mes de diciembre, ya que es en esa fecha cuando el profesor indicó a los alumnos que debían ver la píldora antes de iniciar el tema de Equilibrio Químico.

\section{CONCLUSIONES}

En este trabajo se muestra el uso de un innovador objeto de aprendizaje reutilizable y útil para fomentar y motivar el aprendizaje de los alumnos de Ingeniería Industrial de la Universidade de Vigo, aunque es aplicable a cualquier otra disciplina. Se ha diseñado una píldora de aprendizaje para utilizarla como una herramienta que el alumno debe utilizar previamente a las clases magistrales pero debido a las características de las píldoras de conocimiento puede utilizarse y disponer de ella en cualquier momento. La píldora fue utilizada por la totalidad del alumnado, y además se pudo comprobar que fue utilizada por usuarios a nivel mundial. 


\section{AGRADECIMIENTOS}

Este trabajo ha sido posible gracias a la infraestructura proporcionada por INTEREG TORGA.NET y financiado por la AECID (Proyecto International B/021969/08).

\section{REFERENCIAS}

Chaplin, D.J., Chroma Key method and apparatus, U.S. Patent 5.249.039, (1995).

Drennan, L.T. y M. Beck, Teaching quality performance indicators - key influences on the UK universities'scores. Quality Assurance Education: 9(2), 92-102 (2001).

EME, European Ministers of Education. The Bologna Declaration. Joint declaration of the Ministers of Education, Bologna (1999).

Felder, R.M. y R. Brent, How to improve teaching quality? Quality Manage. J.: 6 (2), 9-21 (1999).

García, I. y Gracia, J., A Methodology Based on Effective Practices to Develop Educational Software. Computación y Sistemas, 11 (4) 313-322 (2008).

Kimovski, G., Trajkovic, V. y Davcev, D., Negotiation-based Multi-agent Resource Management in Distance Education. Proceedings of the IASTED International Conference, Computers and Advanced Technology in Education; Rhodes, Greece, (2003).

Selmer, A., Kraft, M., Moros R. y Colton C.K., Weblabs in chemical engineering education. Trans IChemE, Part D, Education for Chemical Engineers, 2, 38-45 (2007).

Turró C., M. Ferrando, J. Busquets, y A. Cañero, Polimedia: a system for successful video elearning, Eunis 2009 International Conference, Santiago de Compostela 23 a 26 de Junio (2009).

Valderrama, J.O., Sánchez A. y Urrejola S., Colaboración Académica Internacional en Tecnologías de la Información y Docencia Virtual. Formación Universitaria, 2(6), 3-13 (2009).

Wiley, D.A., Connecting learning objects to instructional design theory: a definition, a metaphor, and a taxonomy In The instructional use of learning objects, D.A. Wiley (Ed.) Retrieved may (2009). 